\title{
PHYSICAL AND MECHANICAL PROPERTIES OF RIVER STONE AS COARSE AGGREGATE FOR CONCRETE PRODUCTION
}

\author{
O. M. Ibearugbulem¹, K. C. Igwilo2, *

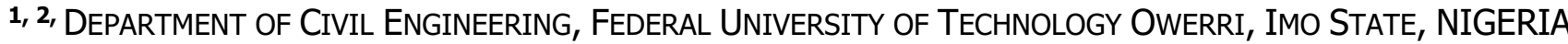
Email addresses: ${ }^{1}$ ibeowums@gmail.com, ${ }^{2}$ kingsleycigwilo@gmail.com

\begin{abstract}
In this research, the physical and mechanical properties of river stone as coarse aggregate for concrete production was investigated. This will provide alternative construction materials to the society especially in areas where there is unavailability of good crushed aggregates. Physical and mechanical tests was conducted on samples of river stone which included; specific gravity of aggregates, bulk density of aggregates, water absorption of aggregates, crushing value of aggregates and grading of aggregates. Results obtained show that the specific gravity value for the sampled river stone is 2.6 . The loose bulk density of the river stone is $1474 \mathrm{~kg} / \mathrm{m}^{3}$. Water absorptions test conducted on the aggregates gave a value of $0.9 \%$. Crushing value of the river stone aggregates was obtained as 34.5. It is recommended that the inclusion of river stone as coarse aggregates in normal weight concrete production be encouraged especially in areas where quality coarse aggregates for normal weight concrete production is scarce and expensive.
\end{abstract}

Keywords: River Stone, Specific Gravity, Bulk Density, Coarse Aggregates.

\section{INTRODUCTION}

Aggregates comprise as much as $60 \%$ to $80 \%$ of a typical concrete mix, so they must be properly selected to be durable, blended for optimum efficiency, and properly controlled to produce consistent concrete strength, workability and durability. The history of good performance of a local aggregate also provides an indication of how well the material performs in service [1].

Good-quality aggregate must be clean, hard, and strong. It must have durable particles and be free of absorbed harmful chemicals, coatings of clay or other contaminations that can affect hydration of cement or reduce the paste-aggregate bond [2]. Steven et al. [2] further expressed that due to heavy increase in the construction activities, the costs of getting these crushed aggregates to places not close to the quarry sites are often too high that in such places the only economical solution will be the use of locally available alternative aggregates such as river stones.

There has been an increasing interest, especially in the developing countries, in the use of these locally sourced coarse aggregate materials in concrete production. This is partly as a result of the unchecked depletion of the natural sources of crushed aggregates, the environmental degradation resulting from the quarry activities and partly as a result of unavailability of these natural sources of crushed aggregates closer to some areas of construction which has resulted to an adverse increase in their prices. Many quarry sites have also been closed after extensive Environmental Impact Assessments were conducted on them because of the damage they cause to the environment.

The problem of scarcity of good crushed aggregates in some areas has been aggravated by the increasing demand in concrete for regular construction purposes. The resulting effect has been a greater demand for alternative construction materials. This has adversely affected the cost of concrete materials, concrete production and construction generally. This problem is of great concern that some attempts have been made to either partially or completely replace crushed aggregates with other materials in concrete production. Such materials have included periwinkle shell, palm kernel shell, sand stones and river stones. The great infrastructure development in many countries, Nigeria inclusive, has led to the 
establishment of many dredging sites resulting in the production of great volumes of river stone. This river stone exists naturally on the river beds and their particle sizes range from 4.75 millimeters to 25 millimeters $(4.75 \mathrm{~mm}-25 \mathrm{~mm})$. It is the need to utilize this river stone and to reduce the need for crushed aggregates that has led to it (river stone) being used in replacement for conventional crushed aggregates in concrete production.

Shetty [3] have it that the size of aggregate bigger than $4.75 \mathrm{~mm}$ is considered as coarse aggregate and aggregate whose size is $4.75 \mathrm{~mm}$ and less is considered as fine aggregate.

Maneeth and Chandrashekar [4], stated that river stone occurs naturally as a round (spherical) aggregate. Classification of aggregates on the basis of shape is an important characteristic since it affects the workability of concrete. From the stand point of economy in cement requirement for a given water/cement ratio, round aggregates are preferable to angular aggregates.

Another property of aggregate is water of absorption. According to American Society for Testing and Materials [5], the water absorbed by aggregates is not considered as part of the free water in the water/cement ratio. Hence, it is good practice to note the aggregate condition before concrete mixing. This will help to know the amount of water required to saturate the aggregate and that for concrete mixing. Kashi et al. [6] studied the water absorption of some aggregates. The result showed that normal weight aggregates have water absorption of less than $2 \%$ and synthetic lightweight aggregates (S. L. A. - made with high composition of fly ash) have water absorption of the range $7 \%-21 \%$.

\subsection{Mechanical Properties of Aggregate}

The strength of aggregates can be evaluated in accordance to BS 812(1975) [7]. Here the ability of aggregate to withstand crushing is determined. This is also covered by American Society for Testing and Materials [8]. The aggregate crushing value gives a relative measure of the resistance of an aggregate to crushing under a gradually applied compressive load. Crushing value tests are commonly carried out for normal weight aggregates. In its place, " $10 \%$ fines value" and "impact value" can be conducted for lightweight aggregates. Different aggregates vary in strength. Some are strong and hard while other are soft and weak. The strength of aggregates goes a long way to determine the strength of concrete made with it.

Another mechanical property of aggregate is the aggregate impact value test. This gives the relative measure of the resistance of an aggregate to sudden shock or impact. This in some aggregates differs from its resistance to a slow compressive load [8].

According to Shetty [3], the aggregate crushing value and the aggregate impact value should not be more than $45 \%$ for aggregates used for concrete other than for wearing surfaces, and $30 \%$ for concrete used for wearing surfaces such as runways, roads and air field pavements.

Concrete production in Nigeria are largely carried out using the conventional crushed aggregates as it has prevalent quantity and availability. Crushed aggregates are produced by mechanically crushing large masses of rock formations at the crushing plant. This process generates 'fugitive' dust which are released in the atmosphere untreated and poses pollution problem [4]. Due to the air pollution problem generated by crushing these aggregates at the crushing plant it is proving hazardous to the environment. More so, Maneeth and Chandrashekar [4] stated that during this mechanical crushing there are chances of attached cracks and weak fragments in the aggregates which may affect its strength in concrete.

Hence, alternative coarse aggregate materials which can be sourced locally, readily available and which poses no hazard to the environment has to be explored.

The river stone has got high potentials for being a natural aggregate. These stones are formed as the flowing water washes over rock particles on the bottom and along the shores of the river. During travel of gravel in river its sizes are reduced naturally without any micro cracking in the aggregates body or any crack and loose fragments attached in it [4].

This present research therefore studied the physical and mechanical properties of the river stone aggregates, which are not only economical but locally available and stances no threat to the environment, and its potential utilization as a coarse aggregate in concrete production.

\section{MATERIALS AND METHODS}

\subsection{Materials}

The major constituent material used in this research was river stone. A sample of river stone aggregate is shown in Plate 1 below. The maximum aggregate size 
of $25 \mathrm{~mm}$ was used in accordance to BS $1881(2013)$ [9].

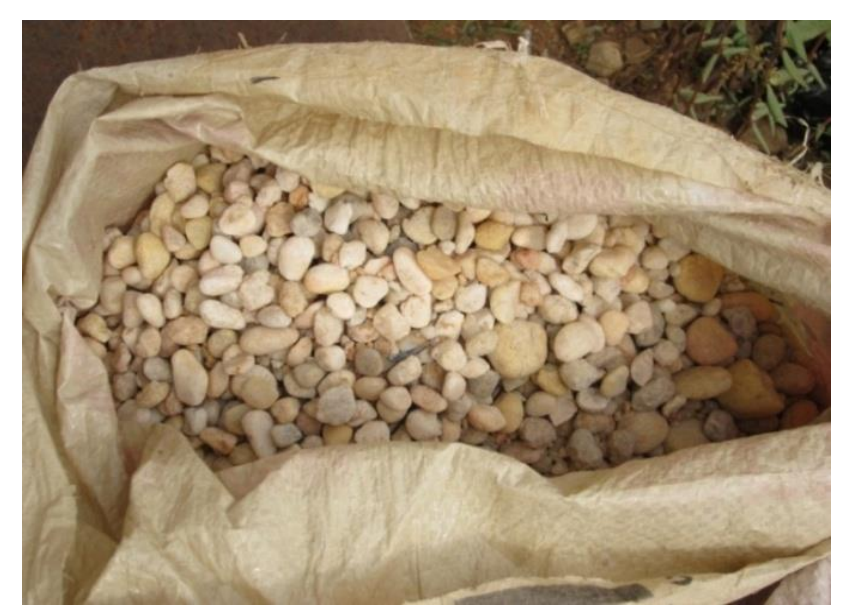

Plate 1: Aggregate (River stone) Sample

\subsection{Methods}

In this research, the Characterization tests of aggregate materials were carried out in the laboratory according to the relevant codes. River stones which were taken from the Njaba river bed, a branch of river Niger in Nigeria, were washed and cleaned to remove the vegetative matters and other deleterious materials adhering to it. The cleaned river stones were graded using the gradation curve.

\subsubsection{Physical Characterization Tests of Aggregate}

Specific gravity, bulk density, water absorption, void ratio and sieve analysis of river stone were tested for. The apparatus used were a $20 \mathrm{~kg}$ weighing machine, four plastic baths, a flat table, a calibrated cylindrical glass jar, hydrometer and scoop. Others were $0.016 \mathrm{~m}$ steel rod, a $0.15 \mathrm{~m} \times 0.15 \mathrm{~m}$ steel cube container, three plastic buckets, three plastic baskets and standard sieves $(37.0 \mathrm{~mm}, 25.0 \mathrm{~mm}, 20.0 \mathrm{~mm}, 14.0 \mathrm{~mm}$, $10.0 \mathrm{~mm}, 5.6 \mathrm{~mm}, 2.36 \mathrm{~mm}, 1.18 \mathrm{~mm}, 0.600 \mathrm{~mm}$, $0.300 \mathrm{~mm}$ and $0.150 \mathrm{~mm}$ ).

\subsubsection{Specific Gravity}

The test was conducted by collecting dry samples of river stones using two plastic baths. The weighing machine with its tray was set to the zero point. The weighing machine was used to weigh the two samples contained in the plastic baths. The masses of the samples were recorded. The hydrometer was used to measure the specific gravity of water. The water was poured into the calibrated bottle after recording its specific gravity. Water level in the bottle was noted and recorded. After recording the water level, the first sample was gradually poured into the bottle containing water. The final level of water was also noted and recorded. The content of the bottle was then discharged into one of the plastic baskets. The process was repeated. Thus, the specific gravity of the river stone was determined as shown in Table 1.

\subsubsection{Bulk Density}

The bulk density test was conducted for compacted and non-compacted samples. For non-compacted sample, the river stones were loosely poured into the $0.15 \mathrm{~m} \times 0.15 \mathrm{~m}$ steel cube container till it was filled. The $16 \mathrm{~mm}$ steel rod was used to level the sample by rolling it over the container. At this point the content of the container was discharged into the tray of the weighing machine, which had been set to the zero point already. The mass of the sample was weighed and recorded. The process was repeated and masses recorded accordingly.

For the compacted samples, the container was filled in three layers using the scoop. Each layer is about one - third of the volume of the container, when the first layer was poured in, the $16 \mathrm{~mm}$ rod was used to tamper the sample 25 times in accordance with American Society for Testing and Materials [10]. This was done for the second and third layers. The container was then filled and the rod was used to level the sample by rolling it over the container. The process was also repeated and the masses recorded. Thus, the bulk density was determined as shown in Table 2 .

Table 1: $\quad$ Specific Gravity test on SSD River Stone

\begin{tabular}{llcc}
\hline \multirow{2}{*}{$\mathrm{S} / \mathrm{N}$} & \multicolumn{2}{c}{ Description of sample } & \multicolumn{2}{c}{ Test Number } \\
\cline { 3 - 4 } & & $\mathrm{A}$ & $\mathrm{B}$ \\
$\mathrm{a}$ & Weight of empty bottle (gm) & 486.22 & 486.22 \\
$\mathrm{~b}$ & Weight of bottle + water (gm) & 1522.36 & 1522.36 \\
$\mathrm{c}$ & Volume of bottle (b-a) & 1036.14 & 1036.14 \\
$\mathrm{~d}$ & Weight of bottle + sample & 1008.38 & 1079.76 \\
e & Weight of sample (d-a) & 522.16 & 593.04 \\
$\mathrm{f}$ & Weight of bottle + sample + water & 1845.66 & 1889.28
\end{tabular}


Physical and Mechanical Properties of River Stone as Coarse Aggregate for Concrete ... , O. M. Ibearugbulem \& K. C. Igwilo

\begin{tabular}{llcc}
\hline \multirow{2}{*}{$\mathrm{S} / \mathrm{N}$} & \multicolumn{2}{c}{ Description of sample } & \multicolumn{2}{c}{ Test Number } \\
\cline { 3 - 4 } & & $\mathrm{A}$ & $\mathrm{B}$ \\
\hline $\mathrm{g}$ & Water added $(\mathrm{f}-\mathrm{d})$ & 873.28 & 809.52 \\
$\mathrm{~h}$ & Water displaced $(\mathrm{c}-\mathrm{g})$ & 198.86 & 226.62 \\
$\mathrm{k}$ & Temperature of water $\left(28^{\circ} \mathrm{C}\right)$ & 0.99626 & 0.99626 \\
& Specific gravity $(\mathrm{e} / \mathrm{h} \times \mathrm{k})$ & 2.616 & 2.607 \\
& Average & \multicolumn{2}{c}{2.612} \\
\hline
\end{tabular}

Table 2: Loose Bulk Density test on Bone-dry River Stone

\begin{tabular}{lcccc}
\hline \multicolumn{1}{c}{ Description } & 1 & 2 & 3 & 4 \\
\hline weight of sample + mould $(\mathrm{kg})$ & 22.555 & 22.470 & 22.565 & 22.495 \\
weight of mould $(\mathrm{kg})$ & 7.686 & 7.686 & 7.686 & 7.686 \\
weight of sample $(\mathrm{kg})$ & 14.869 & 14.784 & 14.879 & 14.809 \\
volume of mould $\left(\mathrm{m}^{3}\right)$ & 0.010065 & 0.010065 & 0.010065 & 0.010065 \\
loose unit weight $\left(\mathrm{kg} / \mathrm{m}^{3}\right)$ & 1477.3 & 1468.9 & 1478.3 & 1471.3 \\
\hline Average loose unit weight $\left(\mathrm{kg} / \mathrm{m}^{3}\right)$ & & \multicolumn{4}{c}{1474} \\
\hline
\end{tabular}

\subsubsection{Void Ratio}

The procedure for void ratio was covered as in specific gravity and bulk density and are calculated as shown in equation 1.

$$
\text { Void ratio }=1-\frac{\text { Bulk density }}{\text { Specific gravity }}
$$

\subsubsection{Relative Density and Water Absorption}

Samples of river stone aggregate were collected using two different bowls. These samples were thoroughly washed to remove finer particles and dust adhering to it and were kept in water for a period of 24 hours. The aggregates were removed from the water and allowed to drain for a few minutes. They were then placed on a dry towel and the surface was gently dried with the towel. The samples were exposed to atmosphere away from sunlight for about 10 minutes until it appears completely surface dried and were weighed (weight A). Afterwards, the aggregates were transferred into different gas jar, filled with water and weighed (weight B). The samples were removed and the gas jar was refilled with water and weighed (weight C). The aggregate samples were then placed in the oven for 24 hours and thereafter, reweighed (weight $D$ ). The process was repeated for the remaining sample. The relative density and water absorption of the river stone was determined as shown in Table 3.

\subsubsection{Sieve Analysis}

The test was done in accordance to BS 812(1975) [7]. The weighing machine was set with its tray to zero point. Then dry samples of river stone were collected and poured into the tray of the weighing machine and the mass was weighed and recorded. The weighed sample was transferred into the set of sieves of sizes $37.0 \mathrm{~mm}, 25.0 \mathrm{~mm}, 20.0 \mathrm{~mm}, 14.0 \mathrm{~mm}, 10.0 \mathrm{~mm}$ ， $5.0 \mathrm{~mm}, 2.36 \mathrm{~mm}$ and was sieved. On completion of sieving, the material retained on each sieve was weighed and the various masses were recorded as shown in Table 4.

Table 3: Water Absorption test on River Stone

\begin{tabular}{lllll}
\hline & Sample number & A & B & Average \\
\hline A & Weight of saturated surface dry aggregate & 600.22 & 600.14 & \\
B & Weight of jar + aggregate + water & 2471.04 & 2466.07 & \\
C & Weight of jar + water only & 2100.04 & 2100.04 & \\
D & Weight of oven dried aggregate & 594.510 & 595.28 & \\
D/(A-(B-C)) & Relative density (oven dry) & 2.594 & 2.544 & 2.569 \\
A/(A-(B-C)) & Relative density (S.S.D.) & 2.619 & 2.565 & 2.592 \\
D/(D-(B-C)) & Apparent relative density & 2.660 & 2.596 & 2.628 \\
$(100($ A-D $) / D$ & Water absorption (\% dry mass) & 1.000 & 0.800 & 0.900 \\
\hline
\end{tabular}


Physical and Mechanical Properties of River Stone as Coarse Aggregate for Concrete ... , O. M. Ibearugbulem \& K. C. Igwilo

Table 4: Particle Size Distribution Tests on River stone, weight of sample $=3.900 \mathrm{~kg}$

\begin{tabular}{cccccc}
\hline Sieve size & Wt. Ret. $(\mathrm{kg})$ & Cum. Wt. Ret. $(\mathrm{kg})$ & \% Wt. Ret. & Cum. \% passing & Cum. \% Wt. Ret. \\
\hline 37.0 & 0.0 & 0.0 & 0.0 & 100.0 & 0 \\
25.0 & 0.350 & 0.350 & 9.0 & 91.0 & 0 \\
20.0 & 0.475 & 0.825 & 12.2 & 78.8 & 21.2 \\
14.0 & 0.890 & 1.715 & 22.8 & 56.0 & 44.0 \\
10.0 & 0.890 & 2.605 & 22.8 & 33.2 & 66.8 \\
5.0 & 0.870 & 3.475 & 22.3 & 10.9 & 89.1 \\
2.36 & 0.280 & 3.755 & 7.0 & 3.7 & 96.1 \\
Pan & 0.145 & 3.900 & 3.7 & 0.0 & 0 \\
\hline Total & 3.900 & \multicolumn{5}{c}{}
\end{tabular}

\subsubsection{Mechanical Characterization Tests of River Stone}

The mechanical characteristics of the river stone was tested by the Crushing value test. The crushing value of river stone was tested using the following apparatus; Steel cylindrical container $(0.148 \mathrm{~m}$ diameter and $0.297 \mathrm{~m}$ height), a standard hammer [7], and $20 \mathrm{~kg}$ weighing machine and scoop. Others were $14 \mathrm{~mm}, 10 \mathrm{~mm}$ and $2.36 \mathrm{~mm}$ standard sieves.

\subsubsection{Crushing Values.}

Some samples of river stones were collected washed and oven dried for 4 hours, the river stones were then sieved using sieves of sizes $20 \mathrm{~mm}, 14 \mathrm{~mm}$ and $10 \mathrm{~mm}$. The materials passing through the $14 \mathrm{~mm}$ sieve and retained in the $10 \mathrm{~mm}$ sieve were poured inside the mold in 3 layers, each layer was tamped with 25 strokes of a tamping rod. The weight of the river stones was measured and the apparatus was then placed in the compression testing machine and loaded at a uniform rate so as to achieve $400 \mathrm{KN}$ load in 10 minutes. The samples were then collected and sieved using the sieve of sizes $2.36 \mathrm{~mm}$ and the material passing through the sieve was weighed. The process was repeated and the mean aggregate crushing value determined as shown in Table 5.

\section{RESULTS AND DISCUSSIONS}

\subsection{Results}

Physical and mechanical characteristics test conducted on the river stone aggregate materials were summarized in Table 6. These tests include; saturated surface dry specific gravity, loose bulk density, water absorption, crushing value and particle size distribution tests.

\subsection{Result Discussions}

The physical and mechanical properties of river stone as summarized on Table 6 which includes the specific gravity, bulk density, void ratio, water absorption, aggregate crushing value and particle distribution (sieve analysis) are seen to be within acceptable limits for normal weight aggregates. This characterization test results are further discussed in the following subsections.

Table 5: Aggregate Crushing Value (ACV) test on Bone-dry River Stone

\begin{tabular}{lcc}
\hline Force used: 400KN & 1 & 2 \\
\hline Mass of test specimen, $\mathrm{M}_{1}(\mathrm{~kg})$ & 2.995 & 2.968 \\
Mass passing 2.36mm sieve, $\mathrm{M}_{2}(\mathrm{~kg})$ & 1.045 & 1.009 \\
Mass retained on 2.36mm sieve, $\mathrm{M}_{3}(\mathrm{~kg})$ & 1.945 & 1.959 \\
$\mathrm{ACV},\left(\mathrm{M}_{2} \times \mathrm{100}\right) / \mathrm{M}_{1}$ & 34.9 & 34.0 \\
\hline \multicolumn{2}{c}{ Mean ACV } & 34.5 \\
\hline
\end{tabular}

Table 6: Summary of Characteristics test results on Aggregates

\begin{tabular}{clcl}
\hline S/No. & \multicolumn{1}{c}{ Test Description } & Test Results & \multicolumn{1}{c}{ Limit for Normal weight aggregates } \\
\hline 1 & SSD Specific Gravity & 2.612 & $2.4-2.7$ according to Road Research Laboratory [11] \\
2 & Loose Bulk Density $\left(\mathrm{kg} / \mathrm{m}^{3}\right)$ & 1474 & $>1200 \mathrm{~kg} / \mathrm{m}^{3}$ for FA and $>960 \mathrm{~kg} / \mathrm{m}^{3}$ for CA according to BS \\
3 & Water Absorption (\%) & 0.900 & $<2 \%$ according to Newman [13] \\
4 & Crushing Value & 34.5 & $<45 \%$ according to BS 812(1975) [7] \\
5 & Particle size distribution & Zone 2 & Well graded \\
\hline
\end{tabular}




\subsubsection{Specific Gravity of River Stone}

From Table 6 , the saturated surface dry specific gravity for river stone is 2.612 . The specific gravity of most natural (normal weight) aggregates ranges between $2.4-2.7$ [11]. 2.612 are obviously within this limit. Therefore, river stone can be classified as normal weight aggregates and good coarse aggregate for concrete production.

\subsubsection{Bulk Density of River Stone}

The loose bulk density of bone-dry river stone is shown in Tables 6 . The mean bulk density of the river stone is $1474 \mathrm{~kg} / \mathrm{m}^{3}$. These values are greater than the minimum bulk density specified by BS 3681(1973) [12]. This standard defines normal weight aggregate as one having a bulk density exceeding $1200 \mathrm{~kg} / \mathrm{m}^{3}$ for fine aggregates and $960 \mathrm{~kg} / \mathrm{m}^{3}$ for coarse aggregate. Thus, the river stone satisfies this condition and can thus be classified as normal weight aggregates.

\subsubsection{Void Ratio}

Void ratios are calculated from the mean values of the bulk density and specific gravity of the aggregates. Hence, the void ratio of river stone is calculated as follows;

$$
\text { Void ratio }=1-\frac{\text { bulk density }}{\text { specific gravity } \times 1000}
$$

With bulk density $=1474$ and specific gravity $=$ 2.612 , void ratio will by (2) become 0.436 . These values showed that void occupied more volume than the solid matter. In other words, greater volume of filler (a mixture of cement paste and sand otherwise called mortar) will be required in a concrete mix when using river stone as coarse aggregate.

\subsubsection{Water Absorption}

The mean value of the water absorption of the river stone is $0.9 \%$ as shown in Table 6 . These values are within the range of values determined for different sizes of aggregates by Newman [13]. Also, Kashi et al. [14] [6] studied the water absorption of some aggregates. The result showed that normal weight aggregates have water absorption of less than $2 \%$. However, the value of water absorption of river stone falls below this limit, which means they can be grouped as normal weight aggregate and will require less water to become saturated. Thus, when using river stone as aggregates for concrete, the water absorption will be put into consideration. The total water required during concrete batching would be water absorption plus free water content.

\subsubsection{Aggregate Crushing Value}

From Table 6, the mean crushing value of river stone is $34.5 \%$. However, BS $812(1975)$ [7] specified maximum value of $45 \%$ for normal weight aggregates to be used in road surfacing, pavements and other concrete works respectively. Hence, river stone satisfied this requirement and can be used to make concrete for any pavement structure and other concrete works which may require a normal weight aggregate.

\subsubsection{Particle Size Distribution Test (Sieve Analysis)}

The result of the sieve analysis as shown in Table 6 where generated from the following equations:

$$
\begin{aligned}
& \text { Quantity passing }=\text { Total mass }- \text { Mass retained } \\
& \qquad \% \text { retained }=\frac{\text { Mass retained }}{\text { Total } \text { mass }} \\
& \text { From this, } \\
& \% \text { passing }=100-\% \text { retained } \\
& \text { Fineness modulus }=\frac{\text { Tot. cum } \% \text { wt. retianed }}{100} \\
& \text { Fineness modulus }=317.2 / 100=3.2
\end{aligned}
$$

Thus, the Fineness modulus of river stone is 3.2 . However, from Grain Size Distribution Curve of Figure 2, $D_{10}=4.67 \mathrm{~mm}, D_{30}=9.283 \mathrm{~mm}, D_{60}=15.053 \mathrm{~mm}$ having $\%$ Gravel $=89.1, \%$ Sand $=7.0$ and $\%$ Fines $=3.7$.

Therefore,

$$
\begin{array}{r}
\text { Uniformity coefficient, } C_{U}=D_{60} / D_{10} \\
C_{U}=15.053 / 4.67=3.22 \\
\text { Coefficient of gradation, } C_{C}=\frac{D_{30}^{2}}{D_{60} \times D_{10}} \\
C_{C}=9.238^{2} /(15.053 * 4.67)=1.214
\end{array}
$$

Thus, the graph of the distribution in Figure 1 shows that the river stone is well graded.

\section{CONCLUSIONS}

The physical and mechanical characteristics tests conducted on river stone aggregates showed that river stone has a saturated surface dry specific gravity of 2.612 , loose bulk density of $1474 \mathrm{~kg} / \mathrm{m}^{3}$, crushing value of 34.5 and water absorption capacity of $0.9 \%$. These physical and mechanical properties are within the acceptable limits for normal weight aggregates, thus river stone can be classified as a normal weight aggregate and good aggregate material for concrete production. 


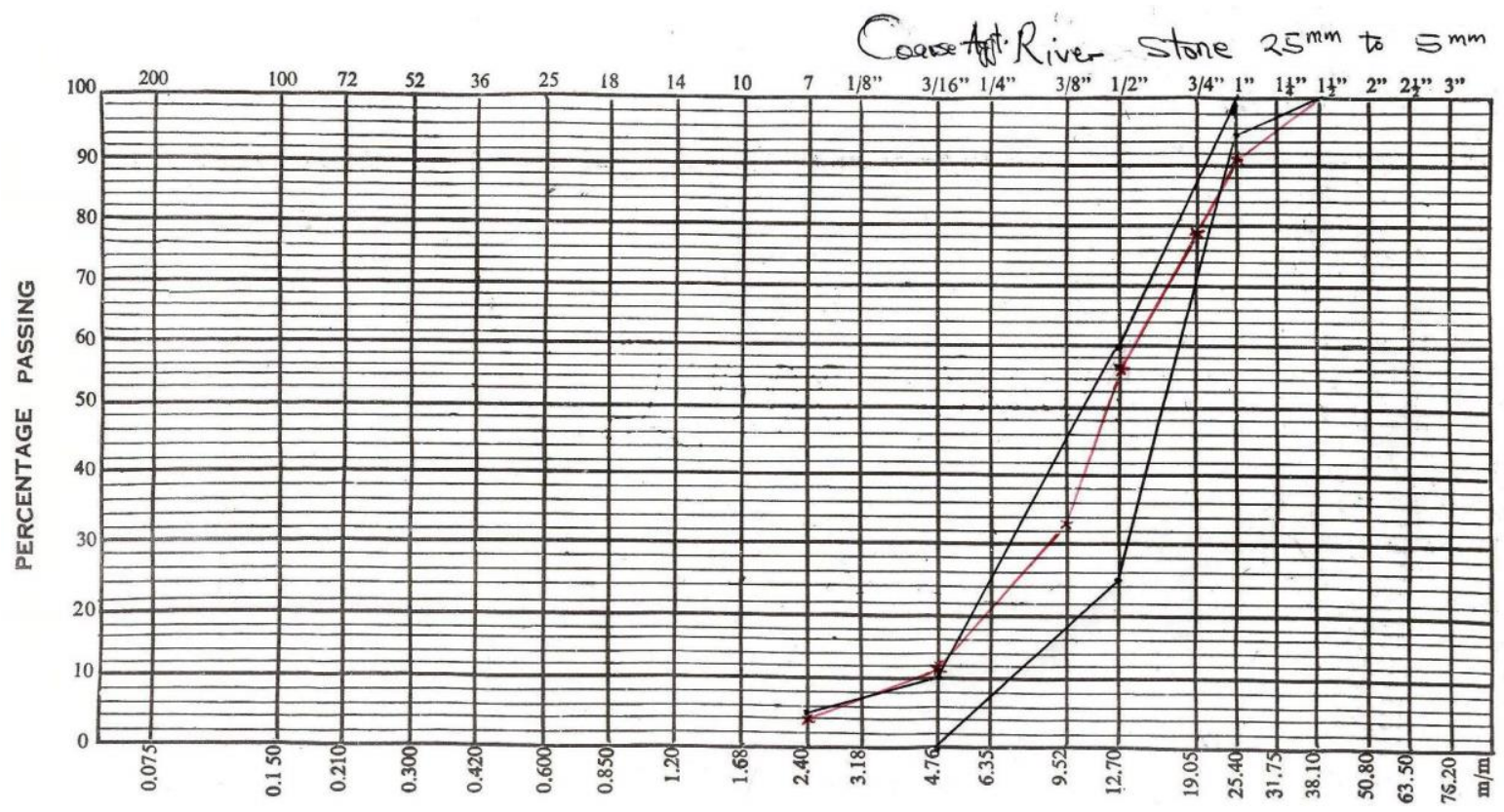

SIEVE SIZES ( $\mathrm{mm})$

Figure 1: Gradation Curve for River stone on semi log graph

In other words, river stone can be used as an alternative coarse aggregate especially in areas where good crushed aggregate is scarce and expensive.

\section{REFERENCES}

[1] Jackson, N. Civil Engineering Materials. Macmillan Press London, 1984.

[2] Steven, H. K., Beatrix K. and Panarese, W. C. Design and Control of Concrete Mixtures. Portland Cement Association, Skokie, Illinois, USA, 2002.

[3] Shetty, M. S. Concrete Technology Theory and Practice. S. Chand \& company Limited, 7361, Ram Nagar, New Delhi, 2005.

[4] Maneeth P. D and Chandrashekar, A. "Performance Appraisal of River Stone as a coarse Aggregate in Concrete" Int. Journal of Engineering Research and Applications Vol. 4, Issue 1(Version 2), Pp.93-102, 2014.

[5] ASTM C125 "Standard Terminology relating to concrete and concrete aggregates". ASTM, West Conshohocken, USA, 2003.

[6] Kashi, M. G., Malloy, R. A. and Swan, C. W. "Fly Ash/Plastic synthetic Aggregate for construction material". Chelsea center for Recycling and Economic Development University of Massachusetts Lowel. Report 45, 2002.

[7] British Standards Institution BS 812 "Methods for sampling and Testing of mineral aggregates, Sand and fillers". British Standards Institution, London, 1975.

[8] ASTM C131 "Standard Test Method for resistance to degradation of small size coarse aggregate by abrasion and impact in loss Angeles machine". ASTM, West Conshohocken, USA, 2003.

[9] British Standards Institution BS 1881 "Testing concrete", Parts 125. British Standards Institution, London, 2013.

[10] ASTM C128-04a "Standard Test Method for Density, Relative Density and Absorption of fine aggregate". ASTM, West Conshohocken, USA, 2001.

[11] Road Research Laboratory "Design of concrete mixes". Road Note No.4, Department of Scientific and Industrial Research, HMSO, London, 1950.

[12] British Standards Institution BS 3681 "Methods of sampling and testing of lightweight aggregate for concrete". British Standards Institution, London, 1973.

[13] Newman, A. J. and Teychenné, D. C. " $A$ classification of sands and its use in concrete mix design", Symposium on Mix Design and Quality Control of Concrete, Cement and Concrete Association, London, Pp. 175-93, 1954.

[14] Kashi, M. G., Malloy R. A. and Swan, C. W. "Development of synthetic Lightweight aggregate for construction materials". Chelsea center for Recycling and Economic Development, University of Massachusetts, Lowell, Report 35, 2001. 